\title{
Editorial
}

\section{Changes to the Journal}

We have made changes to the content of Dams and Reservoirs with effect from this issue. We will no longer publish the list of BDS Committee members here, nor the mini advertisements of our corporate members. Instead, these have been expanded and published in the new BDS Yearbook, which BDS members should have received by now.

The change will enable more technical papers to be included in this journal, while at the same time the yearbook will enable BDS members to become more aware and potentially more involved with the work of the BDS Committee, much of which is currently only briefly referred to in the annual reports. The yearbook will also give corporate members more scope to showcase specific projects undertaken in the last year.

\section{Content of this issue}

A short note by Jacobs' panel engineers identifies the issues faced by panel engineers and undertakers in implementing the recent Ministerial Direction to prepare flood plans for statutory reservoirs in England. This is a very topical matter, and we would welcome discussion and contributions - see below.

In Malcolm Eddlestone's paper he reminds us that in recent years advances in investigation and analysis of earth embankment dams have identified risks of internal erosion. These risks may often be mitigated by the retrofitting of a weighted filter on the downstream toe. The paper draws attention to a number of factors that need to be considered in addition to the key aspect of using the correct filter grading.

Flood detention reservoirs form a major proportion of the new reservoirs currently being constructed in the UK. A paper by Jacobs' panel engineers describes issues regarding risks of failure of such dams, and means by which their resilience may be increased.

Research into the advantages of introducing spherical voids into the body of a concrete gravity dam is contained in a paper by the Construction Research Institute of Egypt. The aim is to reduce the concrete volume and consequently the weight of the dam and hence the required rock bearing capacity.

John Gosden's 2020 Binnie Lecture, which he delivered online, is being published in two parts. The first part, which you can read in this issue, describes three projects which helped John's early development as a dam engineer, and draws out some lessons that he has relied on throughout his career.

\section{Can you contribute?}

We always welcome papers relevant to dams and reservoirs, and if you are considering submitting a paper, please look at the author guidelines inside the back cover of this issue.

We also welcome discussion on the published papers - this might be asking the author for clarification on a point in the paper or providing additional information or comments/views to complement the paper. If you send your discussion to the Editor at editor@britishdams.org as soon as possible after receiving your copy of Dams and Reservoirs, we will do our best to publish it in the next issue.

\section{Value of a Life Year (VOLY) contributed by Alan Brown}

Internationally, research and debate continue as to how governments should evaluate policies which could benefit the public in terms of reduced likelihood of loss of life; brought sharply into focus with the covid pandemic. The UK treasury Green Book 'Central government guidance on appraisal and evaluation' (latest 2018) still advocates use of:

- Value of a Prevented Fatality (VPF) for infrastructure investment, and

- 'Quality Adjusted Life Years' (QALY's) for health interventions.

The former references Department of Transport data at https://www.gov.uk/government/publications/tag-data-book for a quantitative value, which gives a VPF of $£ 1.65 \mathrm{M}$ at 2010 values.

However, these are under periodic review and some now consider that use of 'value of a life year' (VOLY) is more appropriate than VPF as it takes into account the age of those at risk, and would be more consistent with decisions in the health service on when potential treatments provide value for money.

In 2020 HSE published scoping research into the need for primary research to update VOLY, given at https://www.gov. uk/government/publications/valuation-of-risks-to-life-andhealth-monetary-value-of-a-life-year-voly.

For reservoir risk management, VPF can continue to be used for the time being, but in future this may change significantly if VOLY is to be adopted. 